\section{Driving change in implant dentistry}

Dentists and dental technicians from across Great Britain met for a game-changing scientific programme at a special event hosted by Anthogyr in November. Guests at the symposium, held at the historic Brooklands site of Mercedes-Benz World in Weybridge, were treated to an insight into what can be achieved with the Axiom implant range.

Axiom is a high performing system with a conical connection and platform switching suitable for every clinical indication. The flexibility and the simple decision-making process it offers are extraordinary. Keynote speaker Dr Egon Euwe introduced attendees at the 'Accelerate your implant business' conference to the latest technological advance from Anthogyr, Axiom Multi Level.

This unique, user-friendly concept provides optimal crestal bone stability and predictable aesthetic results, for both bone- and tissue-level placement. The easy-to-use inLink connection is precisely engineered to simplify restoration, saving time and money, with flatto-flat surfaces that are tolerated well.

The morse taper design helps to avoid bone loss, providing a tight seal, narrow exit and firm fit. Impressive crestal bone stability

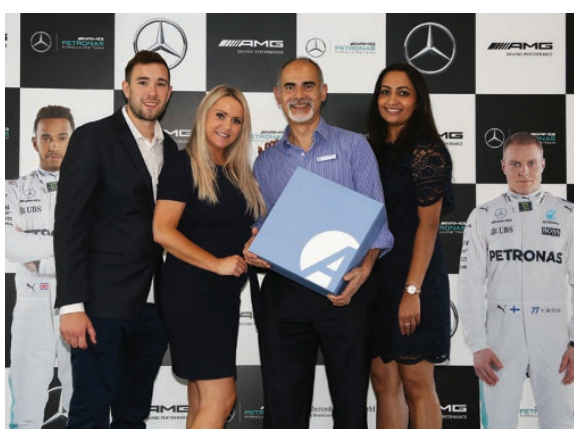

can be obtained from the outset with the Axiom system, by following a few simple rules, such as sub-crestal placement of the implant shoulders. In the long run, this helps to reduce the risk of mucositis degenerating rapidly into peri-implantitis.

The programme of talks at the conference introduced guests to the innovations in implant dentistry that Anthogyr has to offer. Having discussed cutting-edge technology in their own field of dental implantology, delegates were then able to test their skills on the track in high-performance Mercedes-Benz AMGs and in an off-road $4 \times 4$ challenge.

www.anthogyr.co.uk

\section{Hidden cash spreads some joy}

The feel-good factor came to the BDIA Dental Showcase thanks to a campaign by Practice Plan to inspire good deeds.

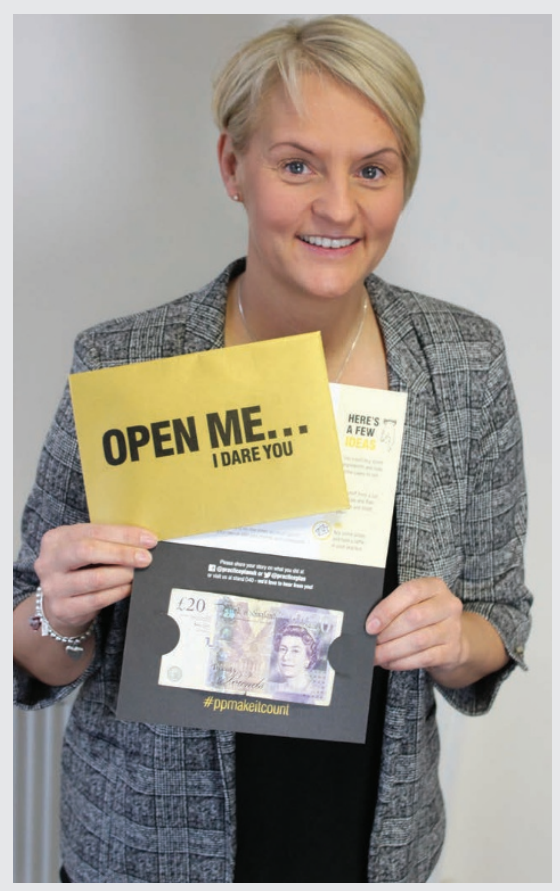

\section{Delivering a perfect} surface finish

With the introduction of the NEW

Essentia Universal Kit, GC have thrown the door to simplification wide open.

Essentia is GC's new light-cured

radiopaque universal composite, which enables clinicians to break free from conventions and eyematch intuitively.

The Essentia Universal shade provides the ultimate solution for posterior restorations because it is a single shade with an amazing blending effect, available in three viscosities. Clinicians can choose between a paste, an injectable and a very

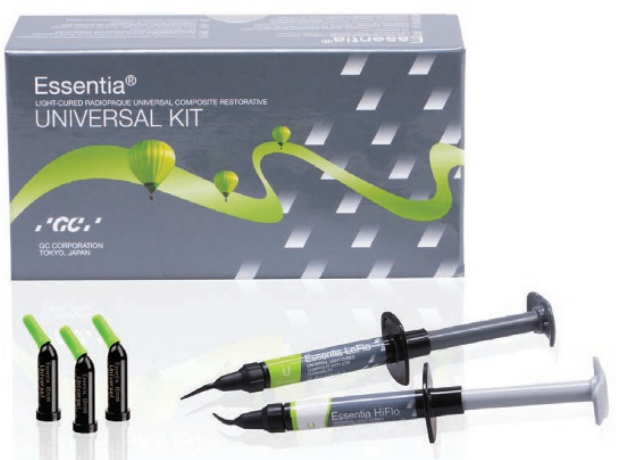

flowable viscosity depending upon what is most useful for each clinical situation. From cervical to occlusal restorations, each version is strong enough for all cavity classes without limitations.

\section{Essentia Universal is now available in} a choice of two promotion packs. Each containing 1 x 2 ml Essentia HiFlo syringe and $1 \times 2 \mathrm{ml}$ Essentia LoFlo syringe; the syringe option also contains $1 \times 2 \mathrm{ml}$ Essentia syringe whilst the Unitip option contains $15 \times 0.16 \mathrm{ml}$ Unitips. They are each available for a recommended price of just $£ 99.00$ plus vat; that’s a $12 \%$ saving against the purchase of individual refills.

Designed by dentists for dentists,

Essentia features optimal handling and optical properties. It also simplifies the polishing procedure, delivering a perfect surface finish in a few steps thanks to its new enamel formulation. Long-term gloss retention being ensured through the use of ultra-fine fillers.

For further information contact GC UK Ltd on 01908 218999, email info@ gcukltd.co.uk or visit www.gceurope.com. 